Strategic Reframing as a Multi-Level Process enabled with Scenario Research

\author{
Authors \\ Dr. Malobi Mukherjee (Corresponding author) \\ Lecturer \\ James Cook University (Singapore Campus) \\ 149 Sims Drive \\ Singapore 387380 \\ Email: malobi123@gmail.com
}

Professor Rafael Ramirez

Professor of Practice \& Director of the Oxford Scenarios Programme Saïd Business School \& Green-Templeton College

University of Oxford OX1 5NY, UK

Dr. Richard Cuthbertson

Research Director

Oxford Institute of Retail Management

Said Buisness School

University of Oxford

OX11HP 


\title{
Strategic Reframing as a Multi-Level Process enabled with Scenario Research
}

\author{
ABSTRACT \\ This paper examines how the scenarios approach enables reframing. Strategic reframing enables \\ individuals to challenge current assumptions and to think afresh about future possibilities, which \\ matters when the context in which strategy operates becomes turbulent. In trying to make sense \\ of the mechanics of reframing created by scenarios intervention we identified specific attributes \\ of a two-way displacement created by scenario research which enables managers to reframe. \\ The first displacement re-centered attention on the macro level uncertainties and reframed both \\ the future macro and meso- levels through iterative interactions without direct reference to the \\ existing micro level. The second displacement involved iterations between the meso and micro- \\ levels to explore future implications at the micro level without requiring immediate action. \\ Drawing on the scenario workshop data and secondary data collected before and after the \\ scenario workshop we propose a process map which highlights the step by step manner in which \\ the scenarios research design enabled the displacement and resultant multi-level reframing. We \\ find that the 'time travel' facilitated by scenarios research provides a future safe space within \\ which the multi-level displacements and subsequent reframing occurs and thereby furthers our \\ understanding of how strategic reframing can overcome micro level myopia when done with the \\ scenarios research process.
}

Key words: Strategy, scenario research, multilevel frames, organizational change, reframing 


\section{INTRODUCTION}

The management literature on framing (Cornelissen and Werner, 2014, Ramirez \& Wilkinson 2016; Schon and Rein, 1994) has invited researchers to offer more detailed examinations of how managerial cognitive reframing takes place. Reframing seeks to develop frames which deviate from existing institutionalized frames to extend, challenge, and create alternative frames -a process referred to in this paper as reframing (Cornelissen and Werner, 2014; p. 216). Reframing matters because such an ability to dissociate from existing cognitive frames enables senior executives in organizations to be better equipped to understand opportunities and challenges, prepare options, and thereby more effectively cope in an increasingly uncertain business environment characterized by novel and unprecedented changes (Benner and Tripsas 2012; Cornelissen and Werner, 2014; Levinthal and Rerup, 2006; Tripsas and Gavetti, 2000). The framing literature has been noteworthy in building on earlier research to help assess how managers as creative agents can re-assemble words and thoughts to actively invoke a different type of frame and thus a different understanding (Diehl and McFarland, 2010; Goffman, 1974); on research of how counter-framing can challenge institutional frames (Lefsrud and Meyer, 2012); and on inquiry about how the relevance of socially constructed frames in frame extension contributes to make frames inter-subjectively meaningful and understandable (Goffman, 1974, Tannen, 1985). Still, Cornelissen and Werner (2014, p.216) found that there is insufficient insight in the existing studies to fully appreciate exactly how the newly created frames can be decoupled from prevailing institutional frames (Weber and Glynn, 2006) as well as freed from relying on the discursive skills or abilities of the actors taking part in the reframing process (Benford and Snow, 2000). Accordingly, Cornelissen and Werner (2014) called for more detailed analyses of 'how' and under 'what' conditions reframing overcomes micro-level 
managerial myopia and static interpretive schema to help managers to cope with unprecedented and novel changes in the business environment (Emery and Trist, 1965; Ramirez, Selsky and van der Heijden, 2008). Our paper seeks to further this line of inquiry by examining how scenarios research - a process which we describe in this paper - enables managers to re-perceive their cognitive frames; and which does so by connecting what scenario planner Wack (1985) famously called the 'microscope' frame in the individual mind to their 'macroscope' framing of the world.

To examine the connection between scenario research and reframing we asked the question 'How does the scenarios approach enable strategic reframing?' To address this question we produce and study two scenario research case studies with retailing organizations seeking to sustain their relevance in environments where a proliferation of disruptive technologies threatened established 'rules of the game'. The two case studies were a real estate firm operating in Asia and a European retail trade association and the projects were carried out by the authors over a three-year period.

We researched how the scenario research sessions helped the senior executives in both cases to reframe at the micro level without referring to pre-existing biases by consider new frames iteratively across multiple levels (macro, meso, and micro) to explore new futures. The paper's contribution is to relate framing scholarship to the step-by-step processes of scenario research and show how reframing operates in practice, providing a link that conforms to practical rationality (Sandberg and Tsoukas, 2011).

The structure of this paper is as follows. We begin by reviewing the framing and scenario research literature. We discuss the methodology and analytical approach to data analysis. The next section details our findings followed by a discussion of our contributions leading to our conclusions. Finally, we consider the limitations of our research. 


\section{Framing and reframing}

The concept of framing has been a feature of the management and organizational literatures at least since its use in the Carnegie research on decision-making in organizations (Cyert and March, 1963; 1993; March and Simon, 1958). It has helped scholars assess a range of cognitive, linguistic and cultural processes within a variety of organizational as well as institutional contexts (Cornelissen and Werner, 2014) and to study ‘sense-giving’ (Fiss and Zajac, 2006).

Framing is understood as the 'schemata' used in interpretation (Snow, Rochford, Worden and Benford,1986) which simplify and condense the 'world out there' by selectively punctuating and encoding events to render them meaningful (Hunt, Benford and Snow, 1994). With a frame one keeps some elements in view while hiding others (Ramirez and Wilkinson 2016; Williams and Benford, 2000). Day and Schoemaker (2005) point out that organization's also need to develop a peripheral vision capability to see issues beyond the familiar frame in order to cope with environmental uncertainties and anomalies.

Framing has been considered at various 'levels' of cognition - micro, meso, and macro. At the micro level, framing has been used to conceptualize and explain internal, self-conscious, cognitive processes of individual sense-making (e.g. Weick 1979, 1995). Micro-level managerial cognition frames refer to an understanding of an individual's 'frame of reference' through which they screen and filter the environment (March and Simon, 1958). At the mesolevel framing has been conceptualized as a socially constructed shared understanding of interorganizational boundaries. These are socially constructed in interactions among managers of firms to jointly produce a common cognitive understanding (Benner and Tripsas, 2012). Nadkarni and Narayanan (2007), referred to such socially constructed frames as 'strategic' frames. These set a shared understanding not only about team, organization, or industry 
boundaries but also about competitive rules and strategy-environment relationships which define a group of firms in a shared domain. At the macro level, typically operating institutionally (Ansari, Fiss and Zajac, 2010), frames can play an important role in the creation and institutionalization of new markets (Lounsbury, Ventresca and Hirsch, 2003; Weber, Heinze and De Soucey, 2008). Bateson (1955, 1972), Burke (1937), and Goffman (1974) researched how common cultural frames of reference are used by actors to define and label experiences in specific contexts that define the very content of institutions.

Frames within each micro-, meso- and macro- levels act as both knowledge structures (Cornelissen and Werner, 2014) and as resources for cognition. However, the literature highlights that over-reliance on pre-existing cognitive frames can support failure when novel, unprecedented, or changing contextual circumstances arise. Existing frames can prevent alternative conceptualizations from being fully considered or assessed - or indeed, acted upon (Benner and Tripsas, 2012; Levinthal and Rerup, 2006; Tripsas and Gavetti, 2000). Bowman (2016) examined how frames as stabilized interpretive schemas can prevent new information transforming into new perceptions at all three levels of analysis. At the micro- level, stable schemas may stem from overreliance on pre-existing cognitive frames, and they can impede the ability for inferential flexibility or alternative conceptualization in changing circumstances (Benner and Tripsas, 2012). Eggers and Kaplan (2013) found that capabilities often become a source of inertia and adaptation to the environment if they fail to take into account considerations of how the interpretation of the possibilities presented by the environment matter for outcomes. Lefsrud and Meyer (2012) highlighted that counter-framing can be coherently connected to and motivated by the personal biographical details of managers and their expertise and worldviews. Research has found that individuals can mobilize their creative ability to reassemble words and 
thoughts to actively invoke different types of reframing (Diehl and Mc Farland, 2010). Yet Cornelissen and Werner (2014 p. 204, 216) suggested that there is in framing analysis a static tendency which may stem from the existing cognitive frame of individuals (Benford and Snow, 2000) or from the collective action frames already established between a group of individuals (Goffman, 1974; Tannen, 1985). Static interpretive schema are not an asset in the context of turbulent environments (Emery \& Trist, 1965; Ramirez et al, 2008), where the unpredictable uncertainties of social, technological, political, environmental, and economic transformations challenge established framing informing options for action; it is in such contexts that better reframing becomes an important capability (Ramirez and Selsky, 2016).

Suggestions of how to overcome micro-level myopia have been given by Vaara and Whittington (2012), who proposed a macroscopic lens in strategizing to overcome micro level myopia. Jarzabowski and Spee (2009) and Normann and Ramirez (1993, 1994) proposed that inter and intra-organizational strategizing facilitates micro-, meso- and macro-level framing. Cornelissen and Werner (2014 p. 216) suggested it would be helpful to develop more processual research to better explore 'how' and 'under what conditions' social interactions leading to reframing can overcome micro-level myopia. According to them, in the absence of such a detailed examination of the processes of reframing, management research in this area will continue to suffer from the risk of tautology, continued use of abstract frames, or be limited to only assess the discursive skills of participants undertaking reframing.

\section{SCENARIO RESEARCH AND REFRAMING}

Scenario research is a rigorous and practical interactive inquiry process (Ramirez et al, 2015) which can be used to enable stakeholders to frame and reframe their current situation. This reframing is articulated through a small, bespoke set of manufactured plausible future contexts 
(the scenarios themselves), which participants produce in the scenario research workshops. That reframing, in turn, stimulates the individual micro-level re-perception of the present situation and helps them to open new options for action (Wack, 1985; van der Heijden, 2005; Ramirez and Wilkinson, 2016 p.10). According to Wack (1985), scenario planning enables managers to reperceive their cognitive frames by connecting the microscope frame on the individual mind to their macroscopic framing of the world. Schoemaker (1995) found that identifying basic trends and uncertainties to construct a set of scenarios helps managers to compensate for the usual overconfidence and tunnel vision in decision making. Wack (1985) and Schoemaker (1995) write about 'scenario planning' as a methodology which has been used in the practice field since the 1950s/1960s to better understand present situations and to identify possibilities for new strategy. Ramirez et al. (2015) show how scenario research can be used as a rigorous and practical scholarly research methodology to help produce 'interesting' research ('interesting' in the sense of Alvesson and Sandberg, 1993). Bowman (2016) explained how scenario research facilitates structured, analytical activities that help scholars to generate new and shared knowledge with practitioners, and to support the generation and acceptance of divergent thinking within stakeholder groups. Scenario research convenes 'polyphony' (Cunliffe and Coupland, 2012) and 'plurivocality’ (Czarniawska, 2008, p. 134) in assessing the environment. The multiple voices in scenario research do not have to agree but they have to be appreciated by the other. In fact, disagreement in this form of research is considered a productive resource rather than a liability to be avoided (Ramirez \& Wilkinson, 2016), and can act as a stimulant to challenge the current (or dominant) thinking frame (Bettis and Prahlad, 1995), helping to overcome cognitive barriers (Bowman, 2016), and to enable reflective reframing (Schon and Rein, 1994), producing ‘knowledge through action’ (Morgan, 1983). Hence, there is no doubt 
that reframing in scenario research can take place. Despite the reframing power of scenario research being well documented in the literature, there is a lack of detailed explanation as to how exactly and when scenario research actually enables the reframing to take place.

This paper welcomes the invitation from Cornelissen and Werner (2014) to explore how and under what conditions social interactions leading to reframing can overcome micro level myopia. Accordingly, this paper reports research on the question 'how does scenario research enable strategic reframing?' It does so through a detailed and critical review of the application of scenario research (as a scholarly research method in accordance with Ramirez et al, 2015) across two case studies, with the aim to better understand the mechanics of strategic reframing created by a scenarios' intervention.

\section{METHODOLOGY}

In this section we highlight details about the two case companies we used for our research and we summarize the phases of data generation and the approaches taken to analyze the data. This scenarios research was a form of action research. The researchers were active collaborators with the case companies in inviting participants for the multi-stakeholder workshops (Eden and Huxman, 1996). Due to their specialized knowledge of the scenario research methodology, the researchers were also actively involved in facilitating the development and use of the scenario frameworks during both research projects (Lüscher and Lewis 2008, p. 223; Gustavsen, 2008).

Case Studies: The first case study was conducted in 2014 for a retail shops trade association (renamed here as Local Shops Association for anonymity, referred to as LSA from here) representing 3000 small and medium enterprises in Europe, many being family-run enterprises. LSA's CEO approached our research team at a time when sales levels through small stores were 
rising as consumers were moving away from using larger stores and were instead using small stores to make more frequent, smaller purchases - while still also buying from discount stores and from online stores. In this changing market, LSA's leadership wanted to better understand the future of local and small store retailing. The second case was conducted for a large international real estate company (renamed Tower Power of TP for short) with a rental turnover in excess of US\$ 2 billion with businesses in Asia, Europe and North America. The newly appointed CEO was concerned that the business environment was becoming increasingly uncertain, with changing shopping patterns moving consumers away from TP-controlled shopping malls, and moving to retailer-controlled alternative physical or online spaces. The CEO therefore wanted to reassess TP’s strategy.

The two cases (used for this paper) were chosen as a pair with similar strategic contexts in retailing and at the same time entailed contrasting organizations (trade body versus real-estate company). Both were generous in offering the researchers access to their organizations before, during and after the scenario research interventions. The similar (retail) context allowed the secondary research necessary for the scenarios to be the same, while the different core participants enabled a comparison of managers with different cultural and sectoral backgrounds. Thus, the context was held constant while the participants were varied (See Appendix 9 for details of participants); helping the scholars to focus the research on the reframing by the participants rather than on the impact of the changing context.

Phases of Data Generation: Our data was generated through desk research, interviews with the senior managers and the CEOs of the respective organizations before the scenario research workshops, the discussions during the scenario research workshop activities, and subsequent meetings with both the CEOs and the employees of the two companies. 
Phase 1 of our data generation comprised a combination of empirical data generated in the oneto-one meetings with the senior managers of the case companies and data from documents researched before the actual scenario research interventions occurred. Our data across the two case companies comprised nineteen market research reports and reviews of contents of three databases on generic future global trends, five company reports on the respective case companies for information about their business models, competitors, key markets and strategic positions, three newspapers reports on the case companies which included interviews with senior managers, and CEO blogs in the case of LSA. The market research reports and databases gave us insights about trends in the broader contextual environment and their possible disruptive influence on businesses. These contextual trends were subsequently used as cues to trigger discussions during the scenario research workshops. The company reports, newspaper interviews and blogs gave us insights into the current perspectives held by the senior managers about their respective businesses and organizations. The initial meetings with the CEOs of the two companies (LSA's CEO gave us four hours spread over two meetings, TP's CEO offered us a one-hour meeting, and in addition helped us to secure three hours with the TP Business Development Director spread over two meetings). These focused on their respective (individual or micro-level) perceptions of the issues emanating from environmental turbulence, areas of concern within their organizations, and desired outcomes of the study. These initial perceptions we later compared with the re-perceptions resulting from the reframing enabled by the scenario research interventions during the data analysis.

Phase 2 of the research generated empirical data comprising two iterations of the scenario frameworks developed during the multi-stakeholder workshops and in meetings between the researchers and senior LSA and TP managers respectively (details found in Appendices 1-4). 
The scenario frameworks were then used to discuss the impact of the future scenarios on LSA and TPs respective businesses with middle and senior management staff. The notes taken by the researchers during these meetings generated another set of empirical data pertaining to the detailed implications of the future scenarios on LSA and TP respectively.

For the multi-stakeholder workshop, key stakeholder groups with a range of macro, meso, and micro perspectives were identified jointly by the research team and LSA and TP senior management respectively (details found in Appendix 9). Multiple individuals from these stakeholder groups were then invited to the workshops by the researchers in conjunction with LSA and TP management. The diverse points of view represented by the variety of participants in the scenario research workshops helped to broaden the set of possible future scenarios with which to generate insights for the present (van der Heijden, 2005). The following line of questioning inherent to scenario planning (van der Heijden, 2005) was used to facilitate the discussions in the workshops (questions i and ii in particular) and the subsequent employee meetings (questions ii and iii in particular):

i) Questions on 'how can trends in the wider contextual environment cause novel, unexpected and sudden surprises in the future' steered the conversation to assess highly plausible yet often ignored trends whose occurrence might cause significant disruption in the broader contextual environment.

ii) Questions on 'how might the combined influence of the novel, unexpected and surprising changes transform the established rules of the game and commonly understood practices governing the industry sectors in the future' steered the conversations to consider possible transformations in the industry sector. 
iii) 'What-if' lines of questioning focused the discussions on the possible new roles or courses of action the two companies (trade body and real estate) would have to undertake if any of the (possibly) transformed future industry sectors came to pass.

The empirical data comprised two iterations of scenario frameworks developed by participants of the multi-stakeholder workshop (depicted in Appendices 1 and 3 respectively), and the research team and senior management following the workshop (depicted in Appendices 2 and 4 respectively). A total of 64 flipcharts, pertaining to the two rounds of scenario iterations were collected during the scenario research workshops and subsequent CEO meetings. The scenario frameworks depicted possibilities on how transformations in the broader contextual environment could take place, and the brief descriptions of how the industry sectors could become transformed in those alternative contextual environments which were drawn and recorded on flipcharts during the workshops and subsequent meetings. These frameworks were supplemented with notes describing the group discussions on how the alternative future contextual environments could evolve and impress upon the relevant business sectors giving rise to future scenario stories about transformations in the relevant business sectors. A sample of the data from the flipcharts is presented in Appendices 1-4.

The scenario frameworks were then used in employee meetings held with middle and senior management staff involved in strategic decision making in LSA and TP respectively, to assess the changing dynamics of the industry sector in each scenario and the resultant business role implications for each organization in those future scenarios, These employees were nominated to attend by the LSA and TP managers respectively and their participation was agreed with the research team to ensure organization-wide representation. The discussions in these meetings were jointly facilitated by the senior LSA and TP managers. Empirical data as notes were 
generated to reflect the discussions where the employees used the imagined future scenario stories to deliberate on how their current business roles would change to adapt to those transformed business sectors. These data notes gave us insights into reframing at the micro level and possible re-perceptions of organizational roles in those future scenarios. Examples of the data notes are highlighted in Tables $1 \& 2$ and additional samples are presented in Appendices $5 \& 6$ respectively.

Phase 3 of the research assessed what strategic transformations were actioned within the organizations after the scenario research intervention was completed. To that effect we verified tentative findings with the respective CEOs via email exchanges and collected more data from press releases and newspaper interviews with senior managers which were published after completion of the projects. Examples of the data are presented in Tables $1 \& 2$ respectively.

\section{ANALYSIS}

We conducted our data analysis after the completion of the two research projects. We approached our data analysis in three different ways, consistent with Langley’s (1999) recommendation for process research, which seeks to understand how and why events play out over time in attempting to extract theory from the ground up (Bower 1997; Pettigrew 1992; Langley 1999). This approach was appropriate for our research as we sought to understand how the activities and conversations facilitated by scenario research led to a transformation of perceptions within the two organizations. We followed Langley's (1999) recommendation and used the Grounded Theory Approach, Temporal Bracketing, and Visual Mapping to analyze the data.

\section{Grounded Theory Approach to coding data}


We first sorted and coded the secondary data on the existing perspectives of the senior managers and the empirical data (from flipcharts and discussion notes generated in workshops and meetings) into first level categories by using the constant comparison method advocated by Glaser and Strauss (1967). So we linked similar types of data on disruptive government policies as 'legislative issues', data on disruptive technological innovation or digitisation as ‘technological issues', data on consumer behavioural issues as consumer issues and so on. In the LSA case $52 \%$ of the data pertained to uncertainties posed by legislative issues, $32 \%$ pertained to consumer issues, $5 \%$ was attributed to technology the remaining $10 \%$ pertained to retail formats, distribution and geopolitical issues. In the TP case $45 \%$ of the data pertained to uncertainties emanating from consumer behavior issues, 31\% pertained to channel (supply and distribution), $20 \%$ to technology and the remaining $4 \%$ to retail formats. Examples of the coding are presented in Table 1 (1.1-1.2) and Table 2 (2.1-2.3) with additional samples presented in Appendices 1-3 for LSA and Appendices 4-6 for TP.

Next, we sought to identify and categorize which micro- meso- and macro level was most salient for each of the first level categories; thereby developing a second level of categories with which to assess frame level characteristics of the data. As we sifted through the raw data to identify the most salient frame levels, and following Ansari, Fiss and Zajac (2010) and Lounsbury, Ventresca and Hirsch (2003), we labelled those first level categories whose disruptive influences were deemed to establish new institutional orders in the broader contextual environment of LSA and TP stakeholders as macro-level. Consumer issues were discerned to disrupt current orders establish new institutional orders in the wider contextual retail environment of TP retail clients \& of LSA members. These macro changes were understood as forces which would impact the businesses of both case companies later as they worked their way from the micro-to the meso- 
and micro-levels. In TP's case, digital channels of delivery; and in LSA's case, national government policies were also categorized as disruptions in the macro-level.

Following the definitions of Benner and Tripsas (2012), all the first level categories with reference to the immediate business context in which the stakeholders of LSA and TP were situated and in which both companies carried out their business transactions were labeled as belonging to the meso-level. In TP's case, these included all references to retail formats (malls, departmental stores, online stores), shopping experience, indoor/outdoor shopping spaces, product and service brands, landlord behaviours and those of TP retail tenants. In the case of LSA, these concerned reference to retail formats (convenience retailers, hypermarkets, local shops) LSA members, costs of running businesses (wages, rents) location of retail formats (suburbs, neighbourhoods). Following the definitions of March and Simon (1958) and Weick $(1979,1995)$ all the first level categories with the words 'our' or 'us' or direct references to LSA or TP were considered to be in the micro-level.

\section{Temporal bracketing}

After coding our data, we adopted the temporal bracketing approach to organize all the coded data under the respective research phases; comprising the activities undertaken before, during and after the scenario research projects. An example of our temporal bracketing analysis is presented in Tables $1 \& 2$ for LSA and TP respectively. Appendices $3 \& 6$ provide a larger sample of temporal bracketing for two companies. According to Langley (1999), temporal decomposition of activities offers an opportunity for structured analysis of processes - which is particularly important if there is some likelihood that multi-directionality of relationships will be incorporated in theorization. Temporal bracketing was relevant for us because it made it possible to compare the discourse across macro- meso- and micro- levels before, during and after the 
scenario research. With temporal bracketing we established that LSA's initial concern was driven by businesses challenges to their meso-level members (Table 1: 1.3), originating from changing trends in the macro-level (Table 1: 1.1) - and so we determined that their focus was primarily on macro- and meso- level issues. In TP's case their initial requirement was a reassessment of their individual understanding of their strategy at the micro-level to help the senior managers cope with challenges in the meso-level where their business interests were situated - their focus was primarily on meso- and micro- level issues (Table 2: 2.2-2.5).

Undertaking temporal bracketing of activities in Phase 2 helped us to determine that the questions posed during the initial scenario research workshop activities focused attention primarily on developing the alternative future macro- and meso- level frames (Table 1: 1.7-1.8; Table 2: 2.8-2.9) by focusing the initial discussion on macro- level critical uncertainties (Table 1: 1.5-1.6; Table 2: 2.6-2.7). We also determined through temporal bracketing that conversations in the one-to-one meetings with the senior managers which we held after the scenario research were focused first on the macro-level critical uncertainties and then on the meso-levels (Table 1: 1.9 1.12; Table 2: 2.9-2.12). In the final meeting with company employees the discussions were focused entirely on the meso- and micro- levels (Table 1: 1.13-1.14; Table 2: 2.13-2.14).

In phase 3 our documentary analysis and follow up conversations with senior managers highlighted that in LSA's case, conversations were now including reference to changing their roles at the micro-level (which they had not considered as much in Phase 1) based on their understanding of changing dynamics at the meso- levels in the future (Table 1: 1.15-1.16; Table 2: 2.15, 2.16). In TP’s case, conversations after completion of the research projects focused on how to alter dynamics with stakeholders in the meso-level to cope with disruptions coming from the macro-level which had not been considered as much in Phase 1. 


\section{INSERT TABLES 1 \& 2 ABOUT HERE}

The temporal bracketing exercise allowed us to establish that the conversations enabled by each step in the scenario research invoked all three frame levels, but they focused on different levels in each phase. Thus, in Phase 2, the multi-stakeholder workshop conversations during the scenario framework development focused primarily on macro-meso levels and the conversations in the employee meetings where the scenarios were put to use invoked the meso-micro levels. In Phase 3, ongoing LSA and TP senior management conversations as per press releases and follow up conversations continued to invoke the meso-micro levels compared to the previous macro meso level conversations in LSA and previous micro-meso level conversations in TP in Phase 1. We captured the up and down movement across the three levels in the graphs depicted in Figure 1. To ensure that we had plotted the movements and captured the three levels correctly we referred back the definitions of macro-meso-micro levels in the literature, confirmed our interpretations with our co-author and cross checked with LSA and TP senior managers that they were the correct macro-meso-micro level contexts of the respective organizations.

\section{INSERT FIGURE 1 ABOUT HERE}

\section{Visual Mapping - why the reframing was happening where it was happening}

In our third form of data analysis we focused on identifying how the scenario research had contributed to reframing at the micro-level. We used the Visual Mapping Strategy (Langley, 1999) for our analysis as these maps can show precedence, parallel processes and the passage of time. This was appropriate for us as we sought to analyze the sequential relations (precedence) and mutual influences (parallel processes) between the scenario research and the transitions in macro-, meso- and micro- levels across the research phases i.e. over the passage of time. The 
figures in Appendices 7 and 8 present how we developed and used visual mapping strategy. We referred to our temporal bracketing analysis and arranged the macro- meso- micro- level categories in the same order in which we had plotted them during the temporal bracketing analysis. Only this time we drew square boxes to depict the macro and meso-levels identified in the 3 phases. We used oval shapes to represent the micro level and we used hexagons to depict the reframed macro-meso-micro frame levels. We then analyzed the sequence in which the questions in the scenario research generated reference to levels by plotting the questions (depicted in shaded banners and labelled alphabetically to depict the sequence in which they were asked) alongside the respective macro-meso-micro levels. We used arrows to depict the direction of flow of the conversation and to assess mutuality in the relations. The Visual Mapping of the scenario research process is presented with sample data sets from each case study in Appendices 7 and 8. Our visual mapping analysis highlighted that the sequence of questions (Questions A and B in shaded banners in figures in Appendices 7 and 8 respectively) enabled a logical progression of discussions whereby the initial stages of the scenario research focused conversations on how in the future various combinations of future macro-level uncertainties could impress upon and transform the meso- level considerations. A total of sixteen possible iterations of how the macro-level uncertainties could transform the meso-level were considered in with workshops and subsequent meetings. We used the vertical double-headed arrows to depict these iterative (up and down) relations between the macro- and the meso- levels.

The next sequence of 'what -if' questions (Appendix $7 \& 8$, Question B in shaded banners) used in the one-to-one meetings with senior managers and then employees, focused conversations on how managers would have to work through every alternative meso-level frame to discern new courses of action and new roles for the organization and their own professionalism at the micro- 
level (Appendix 7 and 8, Question C in shaded banner). Each instance of what-if questioning gave rise to a different macro and meso level frame depicting plausible, relevant and challenging future scenarios for each company to consider at the micro-level. We used the vertical double headed arrows to depict these iterative (up and down) relations between the meso- and microlevels.

Our final analysis with the visual mapping compared the micro-level frames across all three research phases to identify what transformation of perspectives at the micro- level after completion of the scenario research had been obtained, if any. The press releases and interviews with senior managers which were published in the following year after the scenario research project suggested that some shifts in the strategic conversations (van der Heijden, 2005) in both case companies had taken place. The vertical double-headed arrows in the figures in Appendices 7 \& 8 depict the iterative interaction between the meso- and micro- level frames and the horizontal double-headed arrows depict the iterations which at the micro- level led to reperception and to an eventual shift in strategic conversations at the meso level.

The virtual mapping exercise led us to conclude that the pattern of questioning enabled by scenario research led to re-perceptions of future roles at the micro level while considering various courses of action in alternative future meso level frames arising from various combinations of macro level uncertainties.

\section{FINDINGS}

We begin this section by presenting the process map that explains how the scenarios research process enabled reframing across the three levels. We then proceed to highlight, for each case company separately, how the patterns of questioning in scenarios research enabled the 
stakeholders access a novel future space and re-perceive at the micro level by reframing the macro and meso level frames in the future space.

\section{A process map of multi-level framing enabled by scenarios research}

Our process map presented in Figure 2 is grounded in the visual mapping analysis (Appendix 7 and 8) we undertook and explains how scenario research enabled reframing at the micro-level by helping executives who participated in this research with reframing their perspectives at the macro- and meso- levels first. The starting point of the process map is represented by the 'current familiar space’ depicting the LSA and TP senior executives’ micro-meso-macro level perspectives prior to the scenarios research process. The process map then highlights three core enablers i.e. the line of questioning (depicted as enablers $1,2 \& 3$ in the process map) within the scenarios research process which steered conversations to a 'new', broader space - one focused on the future macro-level designated the 'future safe space' in the process map. This broader view provided participants with novel insights concerning possible future connections between contextual factors (at the macro level) and industry sector (at the meso level). In turn, this provided them an opportunity to reconsider options at their individual, micro-level as novel perceptions; and in a way not envisioned by the LSA /TP managers previously. The end point of the process map depicts the shift in strategic conversations between the senior managers and stakeholders after the scenarios research was completed - underscoring the new role appropriate at the present time after having viewed it from the vantage point of the future (safe space) during scenarios research.

INSERT FIGURE 2 ABOUT HERE 


\section{Multi-level reframing with scenario research in the LSA project}

Accessing a novel future space and re-perceiving at the micro-level in the LSA

Recall that the LSA's primary reason for undertaking the scenario research project was to better understand the future of local and small store retailing. This occurred at a time when sales levels through small stores were rising as consumers reduced purchases in large stores and switched to more frequent purchases in small stores, while also purchasing from discount stores and online stores.

The initial framings in LSA highlighted its role as a lobbying body for local shops. Its initial frame focus was on macro- challenges from the contextual environment which changed competitive dynamics, brought forth disjointed /inconsistent consumer shopping patterns across retail formats and legislation affecting operational issues; and rising costs. The impact of these factors was considered to be posing a serious threat to the current operating model of LSA member organizations.

In Phase 2, the patterns of conversation enabled by the scenario research broadened these concerns about the contextual environment into a 'new future space' in two different ways. Firstly, upon taking the bigger, higher faming level picture explicitly and in deliberating on future critical uncertainties with different stakeholders, the workshop conversation invited more and more contrasting perspectives on future macro level changes and their impact on the meso level. This both made the picture more complex but also liberated minds from the narrow set of factors which they had up to then considered. For example, the LSA senior managers’ initial frame on adverse impact of legislations on costs of operating convenience stores and diverting business away from convenience stores to the illegal trade (Table 1: 1.1, 1.3) contrasted with 
workshop perspectives highlighting a future where the operating business model of large retailers could be affected adversely by legislations (Table 1: 1.5; Appendix 5: A 5.7) or a future where legislations favouring local stores could create new growth opportunities for convenience stores (Table 1: 1.9). Conversations on macro level consumer issues extended the limited perspectives on local customers as the primary patrons of convenience stores (Table 1: 1.2) to future possibilities where online convenience shopping could take off or a future where convenience stores became sites for social experiences (Table 1: 1.6, 1.10; Appendix 5: A5.8, A5.18). The discussions on macro level uncertainties also focused on technology, distribution, costs and geopolitical issues impacting the retail sector (Refer to Appendix 5: A5.8, A5.9 for the relevant data).

The second way in which the scenario research workshops steered conversations into a 'new future space' was by enabling counterintuitive thinking through 'what-if' questions on how alternative meso-level industry sectors might evolve under the influence of macro level uncertainties. One such example was the emergence of the ipermarket scenario in which the existing role of convenience stores became obsolete at the meso level (Table 1:1.12) as a result of macro level changes in consumer expectations requiring convenience stores to function as tech-enabled one-stop shops while national legislations restricted the sale of some core product offerings in convenience stores (Table 1.11). This reframed meso level frame countered LSA's initial frame of convenience stores serving 'top-up’ customer needs at the meso level (Table 1: 1.3) and counterintuitively opened up the future possibility of local and small shops operating as down-sized tech-enabled hypermarkets (Table 1: 1.12). Instances of other macro-meso interactions and resultant counterintuitive thinking have been depicted in Appendix 5 (A5.10- 
A5.21) and meso-micro level interactions have been depicted in Appendix 5 (A5.22, A5.24, A5.26).

In the final meeting, re-perceptions about new roles in the reframed meso- levels emerged when the relevance of current business assumptions that LSA was a lobbying body exclusively for local shops (Table 1: 1.4) were questioned, challenging parts of the manager's micro level frame. In the ipermarket scenario for instance, considering a possible new role resulted in reframing the micro level frame where LSA considered extending it's membership base to large retailers and multiples willing to act as local shops in a future (meso- level) where convenience stores had transformed into downsized tech-enabled hypermarkets. Further evidence of reframing at the micro level and resultant re-perception appeared in LSA's website in 2014 where they announced LSA's decision to include large retailers and multiples as members to enable their functioning as an inclusive and broad-based organization in the future (Table 1: $1.15,1.16)$.

\section{Multi-level reframing with scenario research in the TP project}

Accessing a novel future space and re-perceiving at the micro-level in TP

As we stated above, TP's primary reason for undertaking the scenario research project was for the CEO and Business Development Director to reassess TP’s strategy. Their initial framing at the micro level was shaped by their existing meso level frame (where the location and neighbourhood of malls were significant determinants of the mall design, architecture and trademix - Table 2: 2.1, 2.2). The increasingly uncertain business environment where changing shopping patterns were moving consumers away from shopping malls to retailer-controlled 
alternative physical and online spaces (Table 2: 2.3) had triggered their initial need for reassessing their strategy (Table 2: 2.4).

In Phase 2, the patterns of questioning afforded by the scenario research broadened the existing conversations in TP in two different ways. Firstly, by taking the bigger, higher framing level picture and deliberating on future critical uncertainties, the workshop invited different perspectives on future macro level changes and refocused attention to corresponding changes in the meso- level. In one example, conversations during the workshops and subsequent meetings re-centered the focus from meso level issues about the management of physical shopping spaces (product offerings, design and quality - Table 2: 2.1, 2.2) to the significance of consumer experiences during the shopping journey emanating from shifting macro level consumer expectations. In this example, the workshop groups identified uncertainties stemming from a range of experiences that consumers expected in a retail setting such as instant gratification of needs, access to a variety of retail touchpoints together with the option for rich cultural experiences (Table 2: 2.5, 2.9; Appendix 6: A6.4, A6.6). In another conversation, the role of macro level technological developments extended the existing limited perceptions about tradeoffs between technology enabled and offline shopping at the meso- level (Table 2: 2.3) to broader perceptions regarding experiences ranging from seamless online-offline experiences, to those evoking strong emotions to experiences in retail settings where outdoor-indoor boundaries were blurred (Table 2: 2.6; 2.10; Appendix 6: A6.5-A6.7)

A second way in which the scenario research workshops steered conversations to a new future space was by enabling counterintuitive thinking through creative 'what-if' questioning. One such counterintuitive future space was depicted by the Craft World scenario where the reframed meso level required landlords like TP to focus on creating experiences in malls functioning as 
'experience hubs' in hi-touch outdoor and indoor retail settings to fulfil the eclectic needs of diversity seeking customers from the macro level (Table 2: 2.7, 2.8, 2.11, 2.12).This was counterintuitive to TP's initial meso- frame level focused on designing high quality malls and renting out space to those retailers whose product mix offerings aligned with the local culture. More examples of counterintuitive thinking triggered during the scenario research workshops and subsequent meetings with senior managers are presented in Appendix 6 (A6.8-A6.19). In the final meeting with employees, re-perceptions about new roles at the reframed meso level emerged when the relevance of TP's current business assumptions were questioned, and their ex status quo as a real estate developer of good quality malls for retail tenants was challenged at the micro level frame of the managers (Table 2: 2.13).Taking cognizance of a possible new role resulted in reframing the micro level frame where TP had to consider partnering with retail tenants to jointly design the offerings in a reframed meso level where malls were functioning as experience hubs (Table 2.14).This reframing was further evident from the re-perception that retail tenants were being considered long term business partners of TP with whom they were reconfiguring stores to make adjustments and adapt to changes in the retail sector, as per a published interview with TPs retail director in late 2015 (Table 2: 2.15, 2.16).

\section{DISCUSSION}

In the two case studies we examined how a trade body (LSA) and a real estate company (TP) were able to re-perceive their existing organizational roles and shift their strategic conversations with key stakeholders after partaking in scenarios research. We undertook the research for the two companies at a time when the senior managers wanted to determine the future of course of action for their organization in the midst of disruptive changes in the wider contextual and 
immediate business environment. We found that the conversations among stakeholders in the scenario research workshops helped the executives of these organizations - as well as other participants - to examine the bigger picture, and with this broader examination, to reframe mesoand micro-level frames. In addition to going 'up-and-then-down' in terms of levels, the scenarios research process worked from the longer term larger forces which operate in the broader (macro-level) context, to their impact as the future arrives at the meso-level, to the here-and-now in which the micro-level decision-makers worked. We summarized this process in Figure 2. The left-hand side depicts the current frame, the center depicts the future frame invoked by scenarios research and the right hand depicts current frame assessed from the vantage point of the future. The diagram highlights that reframing existing micro level frames independent of any bias is not possible to do directly. But can be achieved with the scenarios research process when the discussion extends out into the macro future space where it is easier for participants to take cognizance of more novel, ambiguous and uncertain factors and provoking counterintuitive frames about the impact on meso level industry factors before returning to consider the implications on organizational roles in their present reality.

Our findings make a twofold contribution to the literature. We contribute to the ongoing discussion in the scenario planning literature by developing a process map to highlight the step by step manner in which multi-level reframing takes place during scenarios research. Our second contribution is to the framing literature. Here we show that scenarios research provides transitional future spaces where managers can abandon their current micro level frame and engage in creative and unbiased discussions about new roles in reframed macro-meso futures without committing to action. 
Scenario planners have considered the future to be a safe conceptual space in which to consider current decisions for many decades (c.f. Wack, 1985; van der Heijden, 2005). This feature is also an essential characteristic of scenarios research, where designing and 'running' a 'safe future space' in ways which resonate with managers' current concerns helps them to reframe and reperceive possible courses of action. In both cases of scenarios research which we report here, the salient analyses were first directed to the macro level uncertainties which were beyond the direct control or influence of the senior managers. This examination surfaced those macro level perceptions and rendered them explicit. In raising and addressing 'what if' questions with the help of alternative macro frames and their effects on future possible alternative meso frames, scenario research facilitated a 'reflective social process' to surface and where possible question existing business assumptions at the micro level. Thus, the examination of the broad, uncertain macro-level contexts enabled workshop participants and managers to re-consider and imagine novel meso-level possibilities. We found that instead of reinforcing existing frames of reference to assess macro level factors (Cornelissen and Werner, 2014) scenario research enabled conversations which 'temporarily displaced' frames of the present so that they could be reconsidered from the future. This 'time travel' facilitated deliberations where tacit and even counterintuitive uncomfortable knowledge became discussible. As happens also in scenario planning, the scenario research workshops acted as transitional spaces (Lewin, 1947; Amado and Ambrose, 2001) where the participants could surface and test different framings creatively without commitment to action (Ramirez and Drevon, 2005). Furthermore, the reframed meso level frames unfroze the quasi-equilibrium stability of organization’s role (Lewin, 1947) brought forth considerations for the adoption of new roles and provided a novel vision for instigating and managing change (Gioia and Chittipeddi, 1991). In this way, the findings reported in this paper 
contribute to refine the extant literature on reframing adopted to overcome firm level inertia, by bringing in a temporality from the future to the present and from the broader context through the meso-level and into the micro-level minds of individuals. This methodology can be thus used to alter collective frames during periods of uncertainty (Kaplan 2008; Benford and Snow, 2000, Giddens, 1984, Bourdieu, 1977).

During the later stages of scenario research, 'reframing' at the micro -level occurred when senior executives re-perceived the role of their businesses and the possible actions which they could take in those roles. Scenario sets made these spaces 'safe' in the Lewinian transitional space tradition, as these conceptualizations allowed their current framings to be compared with alternatives to which one did not (yet) need to agree to and without having to make commitments to them. Without the ability to imagine the future meso level spaces, attempts at reframing would have been influenced by existing biases about macro, meso or micro frame levels similar to those discussed in the literature (Schoemaker, 1995; Vaara and Whittington, 2012, Cornelissen and Werner, 2014). Here our paper suggests that re-perception at the micro level occurs with scenario research when it connects the micro level frame of the managers to the reframed meso level emergent from the reframed macro level, thereby extending Wack’s (1985) view on reperception with scenario research, which he says is achieved by connecting the micro level of the individual manager to their macroscope framing of the world.

\section{MANAGERIAL IMPLICATIONS}

The findings in this paper will help practitioners deploying scenario planning to reframe a situation by helping them to temporarily step out of the business as usual mindset. It will do so by enabling the managers using to engage with uncertainties emanating from the macro level and revisit the core assumptions of their businesses at the micro level by re-perceiving business 
roles in the imagined, reframed future macro-meso contexts i.e. the future scenarios. However, managers need to be aware that in order to realize the full potential of scenario planning and reap it's benefits, they need to invest time and resources in the process (Augier et al, 2018; Foster, 1993).

\section{CONCLUSION}

This paper has articulated, with much detail, how reframing occurs across levels when reframing is enabled with scenarios research. Doing this has provided two contributions -one to framing theory and one to scenario research. For scholarship on framing and reframing, this research shows how reframing occurs in detail and in practice. This reframing is helped by having diverse stakeholders engaging in a structured and creative conversation about the present at lower levels enabled by higher level perspectives from the future on the present. These views are manufactured and used by the stakeholders with the scenario research method. For reframing purposes, all participating scenario producers and users are considered learners (Ramirez and Wilkinson, 2016).

For the scenario research method (Ramirez et al, 2015) the study provides empirical sustenance to the method and reinforces it by articulating it in terms of framing theory (Cornelissen and Werner, 2014, Vaara and Whittington, 2012), allowing the multi-level inquiry which comprises it to be more rigorous intellectually and clearer in its epistemology.

This research is based on an exploration of only two case studies within only one industry retailing, albeit in two very different geographies and contexts. As with all exploratory research, this study was not without limitations. One limitation was that the assessment of the implementation of the revised strategies in each of these cases was beyond the scope of the 
research. The authors propose that longitudinal research extending to implementation and review would be beneficial for our understanding of the actualization of strategic reframing and reperceptions. Further empirical research on the impact of scenario planning enabled reframing and it's impact on organizational value creation would also extend the literature in this area.

\section{References}

Alvesson, M. \& Sandberg, J. 2013 “Has Management Studies Lost Its Way? Ideas for more imaginative and innovative research” Journal of Management Studies, 50:1 128-152

Ansari,S. M. Fiss, P.\& Zajac, E.J. 2010 “Made to fit: How practices vary as they diffuse” Academy of Management Review, 35.1: 67-92

Augier, M., Dew, N., Knudsen, T., \& Stieglitz, N. 2018 “Organizational persistence in the use of war gaming and scenario research”. Long Range Planning.51: pp 511-525

Bateson, G. 1955 “Steps to an ecology of mind” New York: Ballantine (original work published in 1955)

Bateson, G. 1972 "Steps to an ecology of mind: Collected essays in anthropology, psychiatry, evolution, and epistemology”. University of Chicago Press.

Beck, P.W., 1982. Corporate planning for an uncertain future. Long. Range Planning. 15 (4), 1221.

Bettis, R A. \& Prahalad C.K.1995 “The dominant logic: Retrospective and extension” Strategic Management Journal 16.1: 5-14.

Benford, R.D. \& Snow, D. A. 2000 “Framing processes and social movements: An overview and assessment” Annual Review of Sociology 11-639. 
Benner, M.J. \& Tripsas, M. 2012 “The influence of prior industry affiliation on framing in nascent industries: The evolution of digital cameras” Strategic Management Journal, 33, 277-302

Bourdieu, P. \&Richard N. 1977 Outline of a Theory of Practice. Vol.16. Cambridge: Cambridge university press.

Bowman, G. 2016 “The Practice of Scenario research: An Analysis of Inter and Intra organizational Strategizing” British Journal of Management 27.1: 77-96.

Burke, K. 1937 “Attitudes towards history”. New York: New Republic

Cornelissen, J. P., Holt, R and Zundel, M. 2011 "The role of analogy and metaphor in the framing and legitimization of strategic change." Organization Studies 32.12 pp 1701-1716.

Cornelissen J.P. \& Werner M.D. 2014 "Putting Framing in Perspective: A Review of Framing and Frame Analysis across the Management and Organizational Literature” The Academy of Management Annals, 8.1: 181-235

Cunliffe, A. \& Coupland, C. 2012 "From hero to villain to hero: Making experience sensible through embodied narrative sensemaking” Human Relations 65.1: 63-88.

Cuppen, E.2012“Diversity and constructive conflict in stakeholder dialogue: considerations for design and methods” Policy Sciences 45.1 (2012): 23-46.

Cyert, R.M. \& March, J.G.1963/1993 “A behavioral theory of the firm” (2 ${ }^{\text {nd }}$ edition) Englewood Cliffs, NJ. Prentice Hall

Czarwiawaska, B. 2008“A theory of Organizing” Cheltenham, Edward Elgar

Day, G.S. and Schoemaker, P.H. 2005 “Scanning the periphery” Harvard business review 83(11) 135 
Diehl, D. \& McFarland, D. 2010 “Toward a Historical Sociology of Social Situations 1” American Journal of Sociology 115.6:1713-1752.

Durand, R. and Vaara, E. 2009 “Causation, counterfactuals, and competitive advantage.” Strategic Management Journal 30.12 pp: 1245-1264.

Eden, C. \& Huxman, C. 1996 “Action research for the study of organisations”. In Handbook of Organisational Studies. pp. 526-542. Washington: Sage Publications

Eggers, J. P., and Kaplan, S. 2013 “Cognition and capabilities: A multi-level perspective.” Academy of Management Annals 7.1: 295-340.

Emery F E \& Trist E. L. 1965 “The causal texture of organizational environments” Human Relations. 18:21-32.

Fiss, P.C. \& Zajac, E.J. 2006 “The symbolic management of strategic change: Sense-giving via framing and decoupling” Academy of Management Journal 49.6: 1173-1193.

Foster, M.J., 1993. Scenario research for small business. Long. Range Planning. 26 (1), 123-129.

Giddens, A. 1984 "The constitution of society: Outline of the theory of structure. Berkeley."

Granovetter, M. 1973 “The Strength of Weak Ties” American Journal of Sociology 78(6):13601380

Grewatsch, S., and Kleindienst, I. 2018 “How organizational cognitive frames affect organizational capabilities: The context of corporate sustainability.” Long Range Planning 51.4: pp 607-624. 
Glaser, B. and Strauss, A. 1967 “The discovery of grounded theory” London: Weidenfeld and Nicholson 24-25: 288-304.

Goffman, E. 1974 "Frame analysis: An essay on the organization of experience" Cambridge, MA, US: Harvard University Press

Gioia, D. A. and Chittipeddi, K. 1991 "Sensemaking and sensegiving in strategic change initiation.” Strategic management journal 12.6 (1991): 433-448.

Gustavsen, B. 2008 "Action research, practical challenges and the formation of theory”. Action Research, 6(4), 421-437.

Healy, M. P., Hodgkinson, G. P., Whittington, R. \& Johnson, G. 2003 “Off to plan or out to lunch? Relationships between design characteristics and outcomes of strategy workshops” British Journal of Management, 26: 507-528.

Heracleous, L. and Langham, B.1996 "Strategic change and organizational culture at Hay Management Consultants.” Long Range Planning 29.4: pp 485-494.

Heracleous, L. and Jacobs, C.D. 2008 "Crafting strategy: The role of embodied metaphors.” Long Range Planning 41.3: pp 309-325.

Hunt, S. A. Robert D. Benford, R.D. \& Snow, D.A. 1994 "Identity fields: Framing processes and the social construction of movement identities” New social movements: From ideology to identity 185-208.

Jarzabkowski, P. \& Spee. A. P. 2009 "Strategy as practice: A review and future directions for the field” International Journal of Management Reviews 11.1:69-95.

Kaplan, S. 2008 “Framing contests: Strategy making under uncertainty.” Organization Science 19.5 pp: 729-752. 
Kaplan, S. and Tripsas, M. 2008 “Thinking about technology: Applying a cognitive lens to technical change.” Research Policy 37.5: 790-805.

Laamanen, T. and Wallin, J. 2009 “Cognitive dynamics of capability development paths.” Journal of Management Studies 46.6: pp 950-981.

Langley, A .1999 “Strategies for theorizing from process data” Academy of Management review 24.4: 691-710.

Lefsrud, L M. \& Meyer, R.E. 2012 “Science or science fiction? Professionals’ discursive construction of climate change” Organization Studies 33.11: 1477-1506.

Levinthal, D. \& Rerup, C. 2006 “Crossing an apparent chasm: Bridging mindful and less mindful perspectives on organizational learning” Organization Science, 17.4:502-513

Lewin, K. 1947 “Frontiers in group dynamics”. In Cartwright, D. (Ed.), Field Theory in Social Science. London: Social Science Paperbacks.

Lounsbury, M. Ventresca, M. \& Hirsch, P.M. 2003 “Social movements, field frames and industry emergence: A cultural-political perspective on US recycling” Socio Economic Review, 1:71-104

Lüscher, L. S., \& Lewis, M. W. 2008 “Organizational change and managerial sensemaking: Working through paradox”. Academy of management Journal, 51(2), 221-240.

March, J.C. \& Simon, H.A. 1958 “Organizations” New York: Wiley

Morgan, G. (ed.) 1983 “Beyond Method: Strategies for Social Research” London: Sage Publications 
Nadkarni, S. \& Narayanan, V.K. 2007 "Evolution of collective strategy frames in high and low velocity industries” Organization Science, 18.46: 88-710

Normann, R. 2001 "Reframing business: When the map changes the landscape” John Wiley \& Sons.

Normann, R. \& Ramirez, R. 1993 “From value chain to value constellation” Harvard Business Review 71.4: 65-77.

Normann, R. \& Ramirez, R. 1994 "Designing interactive strategy: From value chain to value constellation” 1998. Chichester:Wiley.

Powell, W.W. and Colyvas, J.A. 2008 "Micro foundations of institutional theory” The Sage handbook of organizational institutionalism 276 (2008): 298.

Ramírez, R. \& Drevon, C.2005 "The Role and Limits of Methods in Transitional Change Processes” in The Transitional Approach in Action, G. Amado \& L. Vansina (eds.) pp 192-226. Karnak Books, London.

Ramírez, R. Mukherjee, M, Vezzoli, S. \& Kramer, A.M. 2015 "Scenarios as a scholarly method to produce interesting research”, Futures, 71:70-87

Ramírez, R., Roodhart, L., Manders, W., 2011. How shell domains link innovation and strategy. Long Range Planning 44.4, 250-270.

Ramírez, R.l, and Selsky, J.W. 2016 "Strategic planning in turbulent environments: A social ecology approach to scenarios” Long Range Planning 49.1 (2016): 90-102.

Ramírez, R. Selsky, J. \& van der Heijden, K. 2008 “Business Planning for Turbulent Times: New Methods for Applying Scenarios” Earthscan. 2nd edition. 
Ramírez, R. \& Wilkinson, A. 2016 "Strategic Reframing: the Oxford Scenario Research Approach” Oxford University Press.

Sandberg, J., \& Tsoukas, H. 2011 "Grasping the logic of practice: Theorizing through practical rationality” Academy of management review, 36(2), 338-360.

Schoemaker, P. JH. "Scenario planning: a tool for strategic thinking." Sloan management review 36.2 (1995): 25-50.

Schön, D. A. \& Rein, M. 1994 "Frame reflection: Toward the resolution of intractable policy controversies”. Basic Books.

Snow, D. A., Rochford Jr, E. B., Worden, S. K., \& Benford, R. D. 1986 "Frame alignment processes, micro-mobilization and movement participation”. American sociological review. 464481.

Tannen, D. 1985 “Frames and schemas in interaction”. Quaderni di semantica 6.2: 326-335.

Tripsas, M. \& Gavetti,G. 2000 "Capabilities, cognition, and inertia: evidence from digital imaging”. Strategic Management Journal, 21.10-11:1147-1161

Vaara, E. \& Whittington, R. 2012 "Strategy as Practice: Taking Social Practices Seriously”Academy of Management Annals, 6.1: 285-336

Van der Heijden, K. 2005 “Scenarios: the art of strategic conversation” $2^{\text {nd }}$ Edition, Wiley, Chichester

Wack, P. 1985 “Scenarios: uncharted waters ahead”. Harvard business review

Weber, K., \& Glynn, M. A. 2006 "Making sense with institutions: Context, thought and action in Karl Weick’s theory” Organization Studies, 27:1639-1660 
Weber, K., Heinze, K.L. \& DeSoucey, M. 2008 “Forage for thought: Mobilizing codes in movement for grass-fed, meat and dairy products”. Administrative Science Quarterly,53:529-567

Wieck, K.E. 1979 “The Social Psychology of Organizing”. Reading: Addison-Wesley

Weick, K.E. 1995 “Sense-making in organizations”. Thousand Oaks, California

Williams, R.H. \& Benford, R.D. 2000 “Two faces of collective action frames: A theoretical consideration”. Current perspectives in social theory 20: 127-152

Zietsma, C., and Lawrence, T.B. 2010 "Institutional work in the transformation of an organizational field: The interplay of boundary work and practice work”. Administrative science quarterly 55.2 (2010): 189-221.

Zentner, R., 1982. Scenarios, past, present and future. Long. Range Planning. 15 (3), 12-20. 